\title{
Application of Biotechnology in Medicinal Field
}

\author{
Muhammad Shan ${ }^{*}$, Yasir Ali Khan and Hamza Nazar
}

Center of Agricultural Biochemistry and Biotechnology, University of Agriculture, Agriculture University Road, Faislabad, Pakistan

*Corresponding author: Muhammad Shan, Center of Agricultural Biochemistry and Biotechnology, University of Agriculture, Agriculture University Road, Faislabad, Zip Code 38000, Pakistan, Tel: +923045828344; E-Mail: shansaeed988@gmail.com

Received date: May 22, 2018; Accepted date: August 09, 2018; Published date: August 14, 2018

Citation: Shan M, Khan YA, Nazar H (2018) Application of Biotechnology in Medicinal Field. Single Cell Biol 7:174. Doi: 10.4172/2168-9431.1000174

Copyright: $\odot 2018$ Shan M, et al. This is an open-access article distributed under the terms of the Creative Commons Attribution License, which permits unrestricted use, distribution, and reproduction in any medium, provided the original author and source are credited.

\begin{abstract}
Biotechnology is a very wide area of science and biotechnology itself is a very diverse field with so many advantages. Biotechnology also has various numbers of branches within. This short communication summarizes the application, benefits and trends of biotechnology in the field of medicine. It covers all the areas of medicine which are covered by and advanced by the application of biotechnology. Some of the latest trends in biotechnology are also discussed in this paper. Biotechnology brings out the solutions to a large number of medical problems that will be beneficial for human and give hike to human mortality and morbidity.
\end{abstract}

Keywords: Biotechnology; Medicine; Medicinal application; Plant virus; Breeding; Biotechnology applications; Tissue culture; Metal complexes; Medicinal plants; Germplasm conservation; Plant virus vectors

\section{Introduction}

Biotechnology is the most advance field in scientific research and it is opening various new dimensions and ways to look into various other fields of science. Medicine is one of the most instrumental horizons of biotechnology. To start with, biotechnology provides medicinal plants and these plants, on the basis of their beneficial properties in the field of medicine, are of huge importance. Tissue culture and cell culture of medicinal plants has made possible acquiring the traits of various suitable medicines which is most effective in modern days. Moreover, biotechnology has made possible Haploid breeding of medicinal plants, protoplast culture and Germplasm conservation for preservation of medicinal plants that are of huge value [1].

Photoactiveable metal complexes have opened a new dimension in the application of biotechnology in medicinal field. Biologically active small molecules are released by metal complexes, which are very useful for site directed therapy. This is also extending towards cancer treatments. The application of biotechnology has enabled the metal complexes to be activated or deactivated at will and as the need arises. This in turn has a variety of application of technical aspect of biotechnology for medicine (just like cancer therapy) and other modern day applications [2].

Also, Plant virus vectors have been developed with the help of biotechnological techniques. This vector has great many applications in the field of human medicine. The major applications of this vector are crop production and improvement. Yield of medicinal plants has been greatly improved and are preserved from the hazards of malignant bacteria. This not only increases the production of medicinal plants but also enhances the quality, which is a major concern. Application of biotechnology in medicinal plants provides with hugely improved quality parameters. Moreover, improved quality overall improves the health standards in veterinary and the human side of medicine [3].

\section{Conclusion}

Biotechnology has a huge contribution when it comes to the field of medicine. Biotechnology has tremendous number of benefits for medicinal field. The field of Medicine when overlaps with biotechnology, it generates a beneficial and effective combination which is very helpful for mankind. This combination not only enhances the production which is virus free and sustainable but also this also reduces the risk of various diseases in human beings.

\section{References}

1. Huang HP, Li JC, Huang LQ (2014) The application of biotechnology in medicinal. Chin J Integr Med 2: 1.

2. Smith NA, Sadler PJ (2013) Photoactivatable metal complexes: From theory to applications in biotechnology and medicine. The Royal Society.

3. Scholthof KGB, Mirkov E, Scholthof BH (2002) Plant virus gene vectors: Biotechnology applications in agriculture and medicine. Genetic Engineering: Principles and Methods 24: 67-84. 